\title{
A genealogia da ética como método de ánalise de subjetivações e práticas de si mesmo
}

\section{La genealogía de la ética como método de análisis de subjetivaciones y prácticas de sí mismo}

\section{Genealogy of ethics as historical method of analyses of subjectivations and practices of the self}

\section{Kleber Prado Filho}

${ }^{a}$ Mestre em Administração pela Universidade Federal de Santa Catarina e Doutor em Sociologia pela Universidade de São Paulo (1998), com estágio pós-doutoral em História pela Unicamp. É professor do Programa de pós-graduação em Psicologia da Universidade Federal de Santa Catarina, Florianópolis/SC, Brasil. Endereço institucional: Programa de Pós-graduação em Psicologia. Centro de Filosofia e Ciências Humanas, Campus universitário, Florianópolis - UFSC. 88040-970. E-mail: kleberprado.psi@gmail.com

Resumo: Esta reflexão aprofunda-se no contexto dos estudos e análises desenvolvidos por Michel Foucault na primeira metade dos anos 1980, por ele denominado "genealogia da ética", o qual é também o contexto da sua História da Sexualidade. Essa genealogia traça a história descontínua de uma tecnologia de si que se forma no Ocidente desde a cultura grega antiga, em suas diferentes experiências éticas, apontando rupturas e transformações neste conjunto díspar de práticas ao longo da história. Tal história crítica dessas práticas e relações que o sujeito estabelece consigo mesmo é correlativa de uma genealogia do sujeito moral em nossa cultura, ao dar visibilidade a uma rica diversidade de elaborações, trabalhos e estetizações operados pelo sujeito sobre si mesmo no esforço de constituir-se como sujeito moral. Para tanto, a genealogia da ética aplica um olhar e uma perspectiva singulares, desenvolvendo suas próprias problematizações e estratégias metodológicas em relação aos estudos anteriores do autor.

Palavras-chave: Genealogia da ética; Michel Foucault; Práticas de si; Subjetivação

Resumen: Esta reflexión se profundiza en el contexto de los estudios y análisis desarrollados por Michel Foucault en la primera mitad de los años ochenta, a los que denominó "genealogía de la ética", que es también el contexto de su Historia de la sexualidad. Esta genealogía traza la historia discontinua de una tecnología de sí que se ha ido formando en Occidente desde la cultura griega antigua, en sus diferentes experiencias éticas, señalando rupturas y transformaciones en este conjunto dispar de prácticas a lo largo de la historia. Tal historia crítica de estas prácticas y relaciones que el sujeto establece consigo mismo es correlativa de una genealogía del sujeto moral en nuestra cultura, al dar visibilidad a una rica

Como citar o artigo: PRADO FILHO, Kleber. A genealogia da ética como método de ánalise de subjetivações e práticas de si mesmo. Revista de Ciências Humanas, Florianópolis, v. 53, 2019 DOI: 10.5007/2178-4582.2019.e66190 
diversidad de elaboraciones, obras y estetizaciones operadas por el sujeto sobre sí mismo en el esfuerzo por constituirse. como sujeto moral. Para eso, la genealogía de la ética aplica una mirada y perspectiva únicas, desarrollando sus propias problematizaciones y estrategias metodológicas en relación a los estudios previos del autor.

Palabras clave: Genealogía de la ética; Michel Foucault; Prácticas de sí; Subjetivación

\begin{abstract}
This work deepens in the context of the studies and analyses developed by Michel Foucault in the first half of the 1980s, which he calls the genealogy of ethics, and which was the framework of his History of Sexuality. His genealogy traces a discontinuous history of a "technology of the self" that was formed in the West since ancient Greek culture, in different ethical experiences that point out ruptures and transformations and present a disparate set of practices throughout history. Such critical history of these practices and relationships established by the subject with him/herself is correlative to a genealogy of the moral subject in our culture, since it gives visibility to a rich diversity of elaborations, works, and aestheticizations operated by the subject upon him/herself in the effort to constitute him/herself as a moral subject. In order to do so, the genealogy of ethics applies a singular look and perspective, developing its own problematizations and methodological strategies in relation to the author's previous studies.
\end{abstract}

Keywords: Genealogy of Ethics. Michel Foucault. Practices of the Self. Subjectivation.

\title{
1 A GENEALOGIA dA ÉTICA COMO CONTEXTO DE ESTUDOS E ANÁLISES DE RELAÇÕES ÉTICAS DO SUJEITO CONSIGO MESMO
}

No contexto das análises de Nietzsche e Foucault genealogia é história crítica e descontínua de práticas sociais. Na verdade, uma das influências mais notáveis de Nietzsche sobre Foucault diz respeito à apropriação metodológica que o filósofo do século XX faz daquele do século XIX, em termos da aplicação de um olhar genealógico à história. Não é coincidência que o primeiro tenha escrito em 1887 um livro intitulado Genealogia da moral e o outro, nos anos 1980, tenha se dedicado a traçar uma genealogia da ética, sendo que antes disso, nos anos 1970, havia se dedicado a traçar genealogias do poder. Nas trajetórias de uma genealogia do poder trata-se de relações de $\operatorname{poder}^{1}$. No percurso da genealogia da ética trata-se de práticas do sujeito em relação a si mesmo, práticas de si: todo um conjunto de trabalhos, operações, elaborações e produções que um sujeito exercita e realiza sobre si mesmo, tomando por referência valores, enunciados, normas, estéticas, no esforço de constituir-se como sujeito. Não se trata, portanto, de práticas "ensimesmadas", autocentradas e autorreferidas, individualistas, mas de práticas sociais compartilhadas por sujeitos que vivem em determinado tempo, determinada cultura, em contato com seus artefatos.

Em diferentes momentos, análises e estudos desenvolvidos da perspectiva da genealogia da ética são empregados diferentes termos para designar esse campo de relações éticas do sujeito consigo mesmo: práticas de si, técnicas de si, tecnologia de si, que a rigor não são sinônimos. Uma leitura mais atenta mostra que a designação varia conforme o grau de elaboração do trabalho realizado sobre si mesmo: relação do sujeito consigo mesmo refere-se a uma designação geral que engloba operações diversas do sujeito sobre si; prática de si refere-se a trabalhos sobre si de natureza menos elaborada; técnica de si designa operações mais elaboradas sobre si mesmo; e tecnologia de si envolve maior complexidade de trabalho e articulação entre diferentes técnicas e práticas, compondo um conjunto. Percebe-se nas análises genealógicas certa diferença de complexidade e elaboração entre as denominadas práticas de si da cultura grega antiga ou da cultura romana do cuidado de si romano em relação à tecnologia cristã de si mesmo, de caráter confessional e hermenêutico, mais ainda, em relação à tecnologia moderna de sexualização, operada por um dispositivo que inscreve a sexualidade nos corpos dos sujeitos, ou à moderna tecnologia de individualização, cruzamento de técnicas de objetivação e subjetivação que produz sujeitos como indivíduos identificados, marcados pelo poder, pelas disciplinas e pelo jogo da norma.

Por ética deve-se entender aqui algo bem diferente daquilo que se costuma entender nas tradições da filosofia e das ciências humanas, que a tomam como instância de regulação social, em estreita relação

\footnotetext{
1 A respeito desta questão consultar a referência: PRADO FILHO (2017) A genealogia como método de análise práticas e relações de poder. Revista de Ciências Humanas; Florianópolis; vol.51; s.2; 311-327, citada ao final deste artigo.
} 
com a moral, enfatizando seu caráter reflexivo, consciente e racional, de autorregulação e exercício de autonomia por parte de um sujeito capaz de discernir entre o permitido e o não permitido socialmente, além de ser capaz de calcular as consequências dos seus atos para os outros e para si mesmo. Tem-se aqui uma perspectiva individualizada e individualista de ética, centrada na figura do sujeito racional, do indivíduo livre, autônomo, capaz de fazer escolhas, característica das nossas sociedades ocidentais modernas, capitalistas. É no sentido de distanciar-se deste habitual eixo de problematização que Foucault desloca seu olhar e suas análises para esse literal "domínio" de relações agonísticas do sujeito consigo mesmo experimentadas no trabalho de produzir-se, um domínio que se constitui num emaranhado de linhas de força envolvendo jogos de enunciação e verdade, modos de sujeição e assujeitamento, objetivações, subjetivações, normalizações, também, práticas de resistência e de liberdade.

A genealogia da ética por ele proposta serve de pano de fundo metodológico para a sua "História da sexualidade", projeto que restou inacabado em virtude da sua morte precoce em $1984^{2}$. Esse conjunto de análises históricas relativas às práticas sexuais, postas em íntima relação com as práticas e trabalhos do sujeito sobre de si mesmo em diferentes momentos da história do Ocidente tem sido referido por seus leitores como "o último Foucault", o que não deve ser entendido literalmente como uma "etapa da sua obra". Tanto é inadequado tratar a rica diversidade de ditos e escritos de Foucault como obra unitária, acabada, como não é apropriado classificar e periodizar seus estudos e análises em fases ou etapas. Seu pensamento transgressivo, radicalmente crítico e histórico, resiste a classificações, ordenações, inscrições disciplinares e capturas pela ordem do discurso. Aquilo que marca a importância da sua genealogia da ética para o pensamento contemporâneo é justamente esta possibilidade de pensar de outra forma -de problematizar de outra perspectiva - expressa neste singular tratamento de ética como prática de si, como relação do sujeito consigo mesmo e na não menos original imbricação apontada entre estas tecnologias de si e as práticas sexuais em diferentes momentos da nossa história, que mostram a constituição de diferentes sujeitos éticos e sexuais em diferentes momentos históricos da cultura ocidental, expondo assim não apenas a historicidade da sexualidade como também da própria subjetividade.

Tal imbricação sugere que a sexualidade envolve uma relação ética do sujeito consigo mesmo, mediada por enunciados, valores, pela moral e pela norma que regula o exercício da sexualidade em um tempo, que sanciona ou exclui práticas, atitudes, posturas e comportamentos de uma faixa de normalidade demarcada, inscrevendo uma sexualidade no corpo do sujeito. Isto implica que a sexualidade é da ordem da produção, resulta das operações de um dispositivo: o dispositivo da sexualidade, objeto da análise de A vontade de saber. Decorre daí que ela não é da ordem da natureza, não é natural, não é elemento da natureza humana, portanto é histórica, produção política de um tempo, de uma cultura, resultado de jogos de verdade e enunciação, práticas de objetivação, de subjetivação, de normalização, marcação de identidade, jogos de inclusão x exclusão.

A rigor somente se pode falar em sexualidade na modernidade, à medida que o termo surge apenas no século XIX, como enunciado ligado ao discurso psicanalítico freudiano, o que equivale a dizer que antes disso não havia uma designação que nomeasse este campo específico de experiências éticas do sujeito. Pelo mesmo motivo é inadequado referir-se a um modo de ser ou forma de existência

2 O projeto original da História da Sexualidade foi proposto em 1976, quando da publicação do seu $1^{\circ}$ volume - A vontade de saber - no registro da genealogia do poder, em quatro volumes dedicados à análise de cada um dos quatro grandes dispositivos de sexualização operantes na modernidade, envolvendo: a "histerização do corpo da mulher"; a "pedagogização do sexo da criança; a "socialização das condutas de procriação"; e a "psiquiatrização do prazer perverso". Posteriormente, em 1984, às vésperas da sua morte, na Introdução ao $2^{\circ}$ volume da sua história da sexualidade - O uso dos prazeres - ele virá a anunciar sua intenção de mudança de curso, apresentando seu novo projeto, agora da perspectiva de uma genealogia da ética, atento às relações do sujeito consigo mesmo, ampliado para uma análise das diferentes experiências quanto ao exercício e prática sexual em quatro diferentes momentos da cultura ocidental: a cultura grega antiga da "estética da existência" vol.2; a cultura romana do "cuidado de si" - vol.3; a experiência cristã das "confissões da carne" - vol.4; a experiência da sexualidade moderna - vol.1. O $4^{\circ}$ volume - As confissões da carne - restou inédito quando da sua morte, permanecendo assim até 2018, quando finalmente veio a público na edição francesa, atendendo às expectativas de seus leitores. 
como subjetividade ${ }^{3}$ antes da modernidade, uma vez que este termo surge no discurso kantiano, numa problematização da relação de conhecimento, designando aquilo que dificulta ou impede o acesso à objetividade das coisas, contaminando um conhecimento fidedigno e verdadeiro referente a elas. Surge, portanto, no campo da filosofia do conhecimento, carregado de certa negatividade. No final do século XIX este enunciado irá migrar para o discurso psicanalítico - mais uma vez a psicanálise freudiana - ganhando conotação "psi”, como forma de existência, vida subjetiva, interioridade, singularidade, carregada de sentido, passível de procedimentos hermenêuticos com efeitos terapêuticos e de produção de conhecimento sobre si mesmo. Foucault aponta este estreito vínculo existente entre sexualidade $\mathrm{e}$ subjetividade na cultura moderna - certa implicação recíproca entre estes dois enunciados - porém destaca que esta relação não é da ordem da natureza, não é natural, estas são figuras do discurso dotadas de suposta substância, concretamente produzidas e ligadas entre si por jogos de verdade e enunciação, práticas de objetivação, de subjetivação, de normalização e marcação de identidade. São, portanto, efeitos concretos de jogos de saber x poder.

Não é por coincidência que esses dois enunciados irão se encontrar, se vincular estreitamente e ganhar importância no discurso psicanalítico neste momento. Encontra-se aí em questão um acontecimento da ordem do saber: a emergência de outro sujeito na cultura ocidental, diferente daquele predominara desde o início da modernidade, seja enunciado pelo discurso cartesiano - sujeito da razão - seja pelo discurso kantiano: sujeito do conhecimento. A concepção de sujeito do discurso psicanalítico é crítica da tradição racionalista e positivista moderna, centrada no exercício da reflexão, da consciência e da autonomia. O sujeito da psicanálise não sustenta um domínio sobre si mesmo pelo exercício da razão - "não é senhor dentro da sua própria casa" - não é sujeito da consciência, mas sujeito do inconsciente, e como tal, é sujeito do desconhecimento. Foucault (1997) coloca Freud ao lado de outros dois gigantes do pensamento moderno, alinhados por seus compromissos com a crítica: Marx, por sua crítica ao capitalismo e à sociedade moderna; Nietzsche, por sua ampla crítica aos valores, à moral, ao cristianismo, à política, ao conhecimento e ao sujeito modernos; e Freud por sua crítica ao sujeito da razão, enunciado pela tradição racionalista da filosofia moderna.

Da perspectiva crítica de Nietzsche e Foucault é inadequado, pela força da enunciação e da nomeação - a marcação pelo nome - referir-se a um campo de conceitos, enunciados, valores e práticas e normatividades como "sexualidade" ou "subjetividade" antes de tal acontecimento do saber: a implicação entre jogos de verdade, de enunciação e emergência histórica do objeto. Não existe objeto antes do nome, da nomeação, da enunciação. Não existe objeto a priori, em essência: tudo é histórico. E é desta perspectiva radicalmente histórica que serão apresentadas a seguir as experiências éticas tratadas na genealogia da ética, objetos dos quatros volumes da História da sexualidade, em suas imediatas implicações recíprocas em termos de práticas sexuais e constituição de diferentes sujeitos ético-sexuais em diferentes momentos da história do Ocidente.

\section{A GENEALOGIA DA ÉTICA COMO HISTÓRIA CRÍTICA E DESCONTÍNUA DAS PRÁTICAS DE SI: EXPERIÊNCIAS ÉTICAS NA CULTURA OCIDENTAL}

Este termo "experiência" tal com o empregado no contexto das análises éticas de Foucault merece alguns cuidados e considerações preliminares, uma vez que ele não diz respeito a uma experiência subjetiva de um sujeito humano genérico, designando uma experiência humana essencializada, mas refere-se a uma experiência histórica coletiva à qual encontram-se ligados todos os indivíduos concretos em um mesmo tempo ou cultura, por ele mesmo denominada: "experiência humana historicamente concreta" que, como tal, implica correlação entre domínios de saber, tipos de normatividade e formas de subjetividade.

3 A respeito desta questão consultar a referência Prado Filho e Martins (2007). 
Numa experiência ética, histórica, entram em jogo formas correlativas de relações com a verdade e do sujeito consigo mesmo, formas de acesso à verdade e ao conhecimento de si, além de toda uma diversidade de práticas de si trabalhos, elaborações e estetizações operados sobre si mesmo, nos quais alguém se constitui como sujeito moral. (Prado Filho,2009, p. 233)

Neste sentido pode-se recortar quatro experiências históricas na genealogia da ética de M. Foucault, que fornecem elementos para uma genealogia do sujeito moral e uma história da subjetividade: a ética da estética da existência, característica da cultura grega antiga entre os séculos IV e II AC, tema do II $^{\circ}$ volume da História da sexualidade: O uso dos prazeres, publicado em 1984; a ética do cuidado de si na cultura romana entre os séculos II AC e II DC, tema do III $^{\circ}$ volume da História da sexualidade: O cuidado de si, também publicado em 1984; a ética cristã da hermenêutica de si, predominante no período medieval entre os séculos IV e XVI de nossa era, tema do $\mathrm{IV}^{\mathrm{o}}$ volume da História da sexualidade: As confissões da carne, publicado em francês em 2018; e a ética moderna da hermenêutica do desejo, a partir do iluminismo, marcada por uma problematização da sexualidade, curiosamente, temática do I $^{\mathrm{o}}$ volume da História da Sexualidade: A vontade de saber, publicado em 1976 e escrito no registro da genealogia do poder. Deve-se notar, portanto, que a genealogia da ética e a História da sexualidade apresentam assimetrias cronológicas - a publicação dos seus capítulos e volumes não atende a uma cronologia sequencial - confirmando aquilo que foi afirmado anteriormente quanto à dificuldade e impropriedade de classificar e linearizar as análises e estudos de Foucault como "obra".

Na verdade, este emparelhamento entre as diferentes experiências éticas e os volumes da História da sexualidade não está posto por M. Foucault, nem é tão visível assim: essa relação e o que se apresenta aqui resultam de uma leitura que busca sobrepor a genealogia da ética e a História da sexualidade, até porque ele mesmo faz isso nos volumes II: experiência grega; volume III: experiência romana; e IV: experiência cristã. Mas não o faz no volume I: A vontade de saber, publicado oito anos antes, em 1976, até porque este foi escrito no registro da genealogia do poder, problematizando o bioper e as biopolíticas em suas relações com a sexualização dos corpos dos indivíduos. A vontade de saber trata da experiência moderna da sexualidade, mas a rigor não trata de uma ética moderna, no entanto, coloca elementos fundamentais para que se possa fazer ali uma leitura de uma perspectiva ética, atenta a relações do sujeito consigo mesmo envolvidas no confronto com o dispositivo de sexualização; às elaborações, trabalhos e estetizações operados pelo indivíduo no processo de sexualização; às práticas de subjetivação, de resistência e de liberdade envolvidas nos jogos de marcação da identidade pela norma da sexualidade, esta articulada colagem normalizadora característica da cultura moderna entre subjetividade-identidade-sexualidade: núcleo estratégico do dispositivo de sexualização. Tal olhar e problematização autorizam, então, a falar em uma experiência ética moderna no volume I da Histórica da sexualidade (Foucault,1988a), centrada nesta imbricação subjetividade-identidade-sexualidade, que opera como hermenêutica do desejo.

I - Como anteriormente exposto, a mais antiga dessas experiências refere-se à ética da estética da existência característica da cultura grega entre os séculos II AC e II DC. Como sugere o próprio nome, esta experiência implica centralmente elaborações e trabalhos do sujeito sobre si mesmo no sentido de estetizar-se e produzir-se como obra de arte a ser admirada pelos outros. Trata-se uma ética masculina, viril - proposta por homens, para homens - e também ativa, no sentido nietzschiano do termo: aristocrática, fundada em valores nobres; envolvendo o exercício da força, da vontade de potência, contra o outro, o que sugere formas de existência exteriorizadas.

Este modo de vida e de ser, ativo e exteriorizado, implica uma relação agonísitica do sujeito consigo mesmo no sentido de não se deixar dominar por ninguém e por nada, nem por seus próprios vícios, instintos e paixões, uma vez que nesta cultura o animal nunca deve prevalecer sobre o humano. Tal forma de conduzir-se envolve um domínio permanentemente atualizado sobre si mesmo que 
opera como governo - ético - de si, condição necessária ao exercício do governo - político - sobre os outros, mostra da íntima relação existente na cultura grega antiga entre ética e política - governo de si e governo dos/pelos outros.

Neste momento, como em toda a antiguidade - grega e romana - predomina o princípio ético "ocupa-te de ti mesmo", que centra o trabalho do sujeito sobre si em práticas e exercícios corporais, treinamentos, aplicações no esporte, preparação para a guerra, produção e estetização de um corpo ao mesmo tempo forte, potente e belo: íntima correlação entre uma cultura estética em sentido amplo e um cultivo estético de si. Isso não significa que não se faça presente nesta experiência o princípio "conhece-te a ti mesmo" - até pela constatação da potência da filosofia grega-mas apenas que naquilo que diz respeito às práticas do sujeito em relação a si predomina o "ocupa-te de ti mesmo". Nesta cultura, dominada por valores aristocráticos, a filosofia, assim como a cidadania e a democracia são para poucos: para sujeitos do sexo masculino, nascidos na polis, a mulher, os estrangeiros e os escravos não participam dela.

Nos domínios da erótica - das relações de afeto e das práticas sexuais - o homem grego com frequência mantinha relações eróticas e sexuais com rapazes, concomitantemente à relação conjugal que sustentava com a esposa, sem que isso implicasse julgamentos tais como: imoralidade, traição ou mesmo, homossexualidade. É que nesta sociedade a mulher pertence ao domínio da econômica, do governo da casa, da família, da mulher, dos filhos e dos escravos. Com ela o senhor mantém relações de procriação e aquelas ligadas ao governo da casa. As relações de amor e prazer ele vive com os rapazes, que se encontram inscritos nos domínios da erótica. Portanto não há aí conflito moral, são relações de diferentes ordens. Também não cabe neste momento julgamento de homossexualidade, uma vez que nesta cultura não há polarização da prática sexual entre os do mesmo sexo e de sexos diferentes, não está presente aí a norma da heterossexualidade, que é uma invenção moderna. Ainda, diferentemente da experiência moderna, a prática sexual entre eles problematiza o uso dos prazeres e não o desejo, como a nossa.

II - A cultura do cuidado de si, característica da sociedade romana entre os séculos II AC e II $\mathrm{DC}$, é igualmente uma experiência ética ativa, fundada em valores nobres, onde também predomina o princípio "ocupa-te de si mesmo", porém apresenta diferenças significativas em relação à experiência grega, colocando em evidência uma inflexão e certo desnível dentro da cultura antiga, entre mundo grego e mundo romano. A cultura grega é autenticamente ativa, no entanto, comparativamente, a cultura do cuidado de si mostra um declínio de atividade, à medida que introduz uma racionalidade econômica no âmbito das relações do sujeito consigo, que sugere reduzir o ritmo e a intensidade de vida para ganhar em duração e longevidade. Enquanto na sociedade heroica, apolínea, grega era valor morrer jovem lutando numa guerra, na sociedade aristocrática e burocrática romana era valor morrer velho e sábio, uma vez que a longevidade era uma forma de acesso à sabedoria.

A problematização ética desloca-se de práticas de estetização para práticas de cuidado que implicam uma atenção médica a si e produzem um efeito de medicalização nas relações do sujeito consigo mesmo. Os trabalhos sobre si mesmo envolvem agora a aplicação de regimes e dietas para o corpo, além de alguns exercícios e tarefas para a alma - a askesis - a meditação, o exame de consciência, a escritura de si, o exercício de técnicas mnemônicas, que revelam uma inflexão do sujeito sobre si mesmo, na forma de uma análise quase contábil do seu dia, seus atos, suas memórias.

Esta redução de atividade e intensidade, esta racionalidade econômica regendo as relações do sujeito consigo mesmo, esta atenção médica a si e esta inflexão sobre si são mostras de reatividade. Faz-se importante lembrar que a cultura do cuidado de si encontra-se nos limites do mundo antigo, nas fronteiras históricas com o medievo onde predominam práticas, crenças e valores cristãos, e a marca da cultura cristã é a reatividade. É igualmente importante lembrar que os limites entre estes dois mundos, 
entre estas duas éticas, não são precisos e devem ser vistos não exatamente como um encontro entre culturas mas em termos de embate e confronto entre dois mundos, entre diferentes modos de vida e de ser. Vale lembrar ainda que ao longo dos quatro primeiros séculos de nossa era houve uma difusão de práticas e valores cristãos em Roma que produziu um efeito de corrosão dos valores nobres da cultura aristocrática romana, de extensão tal que irá culminar na cristianização do Imperador e será decisivo para o declínio do Império.

Nietzsche refere-se a este acontecimento histórico, político e cultural como "revolta escrava da moral", quando valores "plebeus", das pessoas comuns, se sobrepõem aos valores nobres, aristocráticos, dos ricos e poderosos, produzindo uma "tresvaloração" dos valores (Nietzsche, 1988). Genealogicamente falando: trata-se do declínio de um mundo, uma sociedade, uma cultura, uma experiência ética, e da emergência de outro mundo, outra experiência ética, com suas tecnologias de si: trabalhos, elaborações, estetizações e formas de cuidado de si mesmo. Deve-se também ao pensamento nietzschiano este jogo de oposição entre atividade x reatividade como características e traços culturais que se expressam nas condutas dos sujeitos. A atividade é positiva, exteriorizada, afirmativa, iniciativa e corporal, implicando exercício, destreza, capacidade e potência: é exercício de vontade de potência; a reatividade envolve aplicação mental, é reflexiva, negadora, retroativa, introvertida, autocentrada, interiorizada e ressentida, usa a fraqueza como força. Vistos de uma perspectiva genealógica o sujeito ativo é exteriorizado, afirmativo e corporal, enquanto o sujeito reativo é reflexivo, interiorizado, ressentido e negador de si mesmo: do seu corpo, seu prazer, seus afetos, seu desejo.

Conecta-se a este jogo de oposição a polaridade também observável entre os princípios que orientam diferentes tecnologias de si em diferentes experiências éticas ao longo da história do Ocidente: o "ocupa-te de ti mesmo" e o "conhece-te a ti mesmo". O primeiro princípio é ativo, afirmativo, exteriorizado e corporal; o segundo é reativo, reflexivo, introspectivo, ressentido e negador de si. Considera Foucault, que na passagem do mundo antigo ao medievo, nessa passagem da cultura do cuidado de si à experiência ética cristã que predomina no período medieval acontece a inversão entre esses dois princípios: até então prevalecera no Ocidente, na cultura antiga, o princípio "ocupa-te de ti mesmo" sobre o "conhece-te a ti mesmo", a partir de agora, no período medieval e na modernidade, passará a prevalecer o princípio "conhece-te a ti mesmo" sobre o "ocupa-te de ti mesmo". Antes, o trabalho sobre si era condição para o conhecimento de si mesmo - inverte-se esta relação - agora, o conhecimento de si é condição para o trabalho sobre si. Nota-se, portanto, uma estreita correlação genealógica entre a "revolta escreva da moral" e a "tresvaloração dos valores" que dela deriva, apontadas por Nietzsche, e esta inversão de princípios entre o "ocupa-te de ti mesmo" e o "conhece-te a ti mesmo", que lhe é contemporânea, mencionada por Foucault.

III - A ética da hermenêutica de si, característica da cultura cristã entre os séculos IV e XVI é reativa, confessional e orientada pelo princípio "conhece-te a ti mesmo", envolvendo formas de existência interiorizadas que implicam o exercício de práticas hermenêuticas de decifração e conhecimento de si.

$\mathrm{Na}$ verdade, é genealogicamente inadequado tratar de um período tão longo - doze séculos particularmente quando a temática se refere a relações do sujeito consigo mesmo na cultura cristã medieval. Mas um acontecimento é demarcador neste contexto: o desenvolvimento das técnicas de confissão no Ocidente a partir do século XIII, após a regulamentação do sacramento da penitência. Até então o trabalho do cristão sobre si mesmo implicava práticas penitenciais: formas diversas de autoexpiação, autopunição, quase sempre aplicadas pelo sujeito sobre o próprio corpo, com o objetivo de demonstrar espiritual e socialmente um reconhecimento da culpa e seu esforço no sentido de se corrigir, purificar-se e se reconciliar com a comunidade social e religiosa. Com a emergência das técnicas de confissão a relação do sujeito consigo mesmo torna-se cada vez mais verbal, reflexiva confessional - centrada em si mesmo, interiorizada, um exercício de conhecimento de si. A confissão 
nasce no contexto da fé e da Igreja Católica, porém rapidamente transborda o contexto das práticas religiosas, difundindo-se amplamente nas sociedades ocidentais, laicizando-se como prática social e profissional, na justiça, na medicina, na escola, na psicologia, na psicanálise, na família, passando a constituir uma poderosa tecnologia de conhecimento da si e do sujeito, em vários campos e disciplinas.

Como sugere o título do volume IV da História da sexualidade - As confissões da carne (Foucault, 2018) - o objeto da confissão neste contexto é centralmente a "carne": termo empregado na doutrina cristã para designar o sexo e as práticas sexuais, com foco nas "tentações da carne". Na cultura cristã medieval o sexo e tudo ligado a ele é considerado sujo, perigoso, ardiloso e demoníaco. Esta conotação pejorativa e esta vigilância confessional dão mostra do (des)valor atribuído ao corpo - à "matéria": sua fraqueza, suas ilusões - em relação à "alma": "verdadeira essência" do cristão. Em consequência disso os trabalhos deste sobre si mesmo visam estetizar a alma, conhecê-la, fortalecê-la e purificá-la objetivando alcançar a salvação, o que exige transcender o corpóreo: abrir mão dos prazeres, do sexo, evitar as compulsões, tentações e pensamentos insidiosos ligados à matéria. Isso implica negar o corpo, recusar o sexo e renunciar aos prazeres a eles ligados: uma ascética do corpo correlativa de uma ascética do pensamento.

A confissão é uma estratégia de vigilância do pensamento que objetiva, entre outras aplicações, produzir conhecimento sobre si mesmo. Para tanto, deve ser antecedida de um "exame de consciência", outra prática cristã de si: separar os bons dos maus pensamentos; exercer controle sobre eles; distinguir a verdade da mentira, da falsidade e das ilusões; colocar em questão seus próprios pensamentos, palavras, atos, desejos e intenções, conhecer-se a partir desse exercício e dizer ao confessor a verdade produzida a respeito de si mesmo: o ato de veridicção, que fecha o ciclo de operações do dispositivo confessional cristão sobre o pensamento. Para que esse trabalho sobre o pensamento se transforme em conhecimento de si é necessário que opere como hermenêutica de si, como tecnologia de decifração de si mesmo.

Decorre desta veridicção e do julgamento do confessor - das penitências por ele impostas - o trabalho a ser realizado pelo sujeito em termos de um alinhamento entre alma/pensamento e corpo, de fazer esse conhecimento de si operar sobre ele, produzindo uma ampla renúncia a si mesmo. Esta é a síntese do modo de subjetivação cristão: vigilância do pensamento; conhecimento de si; veridicção; negação do corpo e renúncia a si mesmo. As formas cristãs de existência são reativas em vários sentidos: por privilegiar o conhecimento de si em relação ao trabalho sobre si, ou, priorizar o pensamento em relação ao corpóreo; por levar o sujeito manter uma relação interiorizada consigo mesmo; por fazê-lo aplicar a própria força contra si mesmo, em atos de recusa, negação do corpo e dos prazeres, de renúncia a si mesmo; e ainda, em última instância, por induzi-lo a negar-se a viver a vida material cotidiana com intensidade, em virtude da promessa de uma suposta vida eterna incorpórea. Foucault chega a afirmar, no curso por ele ministrado no Collège de France no período letivo de 1981-1982, intitulado: A hermenêutica do sujeito (Foucault, 2002), que o cristianismo inventa a interioridade à medida que cria uma relação interiorizada do sujeito consigo mesmo, mais uma vez historicizando, criticando a naturalização e a essencialização das formas ocidentais de existência enunciadas pelo discurso moderno.

IV - A ética moderna, caracterizada como hermenêutica do desejo, é complexa e multifacetada, recebe aportes de todas as experiências anteriores a ela - além de introduzir seus próprios artefatos formando uma "bricolagem", um mosaico bastante diversificado de práticas e técnicas de si mesmo, o que expõe, em termos genealógicos, uma relação de proveniência entre elas. Esta modalidade de relação histórica não diz respeito a uma reprodução mecânica de experiências ou mera replicação

4 Este termo - "bricolage", em francês - foi utilizado n os anos 1970 por Deleuze e Guattari no livro "O anti-édipo" (citado nas referências), para designar uma composição de elementos díspares e desconexos, cujo conjunto produz um efeito estético de harmonia e coerência, assemelhando-se à figura do mosaico. 
de práticas, mas supõe que o elemento importado de outro tempo, outra cultura, assumirá diferentes formas e conotações na experiência atual, relativamente ao contexto do qual provém.

Da ética grega da estética da existência a experiência moderna herda práticas de estetização de si mesmo que tomam como objeto não exatamente a vida, a ser produzida como obra de arte, mas esta figura tão emblemática da modernidade, esta forma de existência moderna, que é a subjetividade, a ser cultivada em sua singularidade individualizada. Esta diferença de registro histórico, este deslocamento de objeto em relação à produção da vida como obra de arte, permite falar em uma estetização da subjetividade, particularmente na narcísica cultura contemporânea. Da cultura romana do cuidado de si a experiência ética moderna herda uma diversidade de contenções e restrições impostas pelo sujeito a si mesmo, cuidados dietéticos e com a saúde, articulados a elaborações estéticas, que se avolumam e se sofisticam de tal forma no transcorrer da modernidade, que permitem falar contemporaneamente em atenção médica a si, governo médico do sujeito sobre si mesmo, medicalização das condutas cotidianas e da própria vida, como desdobramentos dessa tecnologia de cuidado em relação a si mesmo.

Já, as relações de proveniência com a experiência ética cristã são mais complexas, articuladas e diversificadas. Acontece nessa transição histórica um amplo fenômeno de laicização de práticas inscritas num registro moral, religioso, recolocadas num registro leigo, social, racionalista e científico - sim, porque assim como a subjetividade, a ciência é uma invenção moderna, forma de conhecimento característica da cultura moderna. Exemplo disso é a técnica de confissão, nascida num contexto religioso, que ganha as ruas difundindo-se amplamente no Ocidente como tecnologia social e profissional. Há também importantes deslocamentos de problematização a serem destacados nessa passagem: da concepção cristã de "carne" para o conceito moderno, científico, de sexualidade, atribuído ao discurso psicanalítico e, em estreita correlação com este, o deslocamento de uma hermenêutica de si para uma hermenêutica do desejo - de um conhecimento de si centrado nas relações morais entre a "alma" e a "carne", para um conhecimento de si produzido a partir de uma problematização científica das relações entre a subjetividade e a sexualidade, também atribuído à psicanálise freudiana.

Outra proveniência relevante nessa passagem da experiência ética cristã à moderna refere-se às questões da reatividade e interioridade do sujeito em suas relações com o conhecimento de si mesmo. Prevalece nas duas éticas o princípio "conhece-te a ti mesmo" sobre o "ocupa-te de ti mesmo", porém os conhecimentos sobre si mesmo produzidos nessa primazia são de diferentes ordens, expondo outro deslocamento: enquanto o conhecimento cristão de si refere-se à "alma" e é de natureza moral e religiosa, o conhecimento do sujeito moderno a respeito de si mesmo refere-se à subjetividade e coloca-se num registro científico, social e psicológico, apresentando-se como teoria sobre a subjetividade. De forma análoga, tanto o sujeito cristão quanto o moderno são interiorizados, porém, trata-se de interioridades diversas entre si: enquanto a interioridade cristã é de natureza espiritual e refere-se à "alma", a interioridade do sujeito moderno refere-se à subjetividade e é de natureza psicológica. Também as formas de reatividade em questão nas duas experiências éticas são diversas: enquanto o trabalho reativo do cristão sobre si tem como objeto a "alma" em suas conexões com a questão da "carne" e implica autoexpiação, reconhecimento de culpa, renúncia ao corpo, aos prazeres, a si mesmo - certa mortificação ou morte em vida - o trabalho do sujeito moderno sobre si, não tão reativo quanto o do cristão, toma como objeto a subjetividade em suas conexões com a questão da sexualidade - problematização moderna da definição de uma "identidade sexual" - envolvendo uma elaboração de si mesmo como sujeito singular, subjetivo e sexual.

Talvez o que mais distinga a ética moderna daquelas que a antecedem é a constatação de que ela é racionalista - centrada na figura do sujeito da razão e do conhecimento - individualizada e individualista, centrada na figura do indivíduo livre e autônomo em princípio. No entanto é importante lembrar que o sujeito da razão é uma figura do discurso moderno, mais especificamente do pensamento cartesiano, como o indivíduo é uma produção do discurso liberal ao longo dos séculos XVII e XVIII, que enuncia o estatuto do indivíduo como norma para o exercício da individualidade. 
O sujeito da razão, de direito, a cidadania, a individualidade, a identidade, a privacidade, a interioridade assim como a subjetividade são formas modernas de existência, que fornecem pistas relativas aos modos modernos de subjetivação, no sentido de compreender como este sujeito torna-se indivíduo normalizado, marcado por uma identidade centralmente sexual em jogos de verdade e poder de dispositivos ${ }^{5}$ de individualização e sexualização. Foucault aponta em A vontade de saber (Foucault, 1988a) a intrínseca relação genealógica existente na cultura moderna entre subjetividade, individualidade, identidade e sexualidade, ligados por jogos do dispositivo, ressaltando que a problematização da sexualidade coloca-se no cerne dos modos modernos de subjetivação. É também neste livro, onde ele propõe ainda fazer uma arqueologia da psicanálise, o que mostra a importância do pensamento freudiano para a modernidade, exatamente por estas questões aqui tratadas.

Práticas de normalização e subjetivação são elementos fundamentais dos jogos de um dispositivo, resta então analisar, da perspectiva da genealogia da ética, como alguém se reconhece ou não como sujeito da norma e a subjetiva: se assujeita e/ou resiste a seus jogos de verdade, constituindo-se assim como sujeito moral e sexual.

\section{A GENEALOGIA DA ÉTICA COMO ESTRATÉGIA DE ANÁLISE DE SUBJETIVA- ÇÕES E PRÁTICAS DE SI}

Conforme afirmado anteriormente, pode ser problemático falar em método nas análises de Foucault, ou, caso se possa falar em método, de forma alguma pode-se falar em metodologia, uma vez que trata-se em seus estudos de indicações mais gerais de direções de pesquisa, problematizações, estratégias de abordagem, nas suas palavras: "regras de prudência", (Foucault, 2002) nunca de procedimentos de pesquisa, prescrições a priori ou regras metodológicas predefinidas. Porque em suas análises o método é construído em íntima correlação com o objeto de estudo: cada genealogia é uma genealogia e cada pesquisa genealógica requer a construção de um método estrategicamente apropriado ao seu objeto. Dessa perspectiva, portanto, uma aplicação genealógica é sempre única e singular.

Dito assim, pode parecer que ele não se preocupa, ou se ocupa, da questão de método. Ao contrário, porém, deve-se notar que todos seus estudos genealógicos publicados como livros apresentam na sua introdução ou entrada, suas estratégias metodológicas, domínios de relações em questão, correlações de saber/poder em jogo, além de problematizações. Isso acontece em Vigiar e Punir (Foucault, 1987); no estudo sobre Pierre Rivière (Foucault, 2003); em A vontade de saber (Foucault, 1988a); em O uso dos prazeres (Foucault,1988b); e em O cuidado de si (Foucault, 1985), evidenciando que as análises de Foucault se ancoram em pesquisas históricas conduzidas e realizadas com muito rigor. No entanto, seu rigor metodológico não é positivista, mas envolve compromisso crítico em problematizar de forma diferente, deslocar-se do habitual e pensar diferente, envolve rigor filosófico na leitura de textos utilizados como suporte, também rigor no tratamento da história em termos de perspectiva, na prática da pesquisa histórica: cuidado histórico e físico com os documentos, ainda, rigor com o uso das palavras, dos argumentos, nos textos, nas aulas, em seus ditos e escritos.

A análise genealógica implica um modo crítico e descontínuo de olhar histórico, voltado aos acontecimentos e rupturas em domínios de práticas e saberes postos em correlação, numa relação de implicação recíproca. O que está em jogo são relações móveis e transitórias: correlações instáveis de força, jogos de verdade, enunciações, práticas de objetivação, de subjetivação, de resistência e de liberdade - porque "onde há poder há resistência" - também, porque o sujeito é constituído e se constitui no ponto de confluência de práticas de objetivação e de subjetivação, em jogos de saber/poder.

Apesar de parecerem termos sinônimos, práticas de subjetivação e modos de subjetivação dizem respeito a coisas bem diferentes: o emprego do termo "modo de subjetivação" diz respeito a fluxos

5 Maiores detalhes a respeito desta complexa e fundamental questão dos dispositivos de poder nas análises genealógicas de Michel Foucault consultar a referência Prado Filho e Teti (2013). 
molares, efeitos da ação de dispositivos, jogos de normalização, instâncias maquínicas de produção da subjetividade e do desejo, segundo Deleuze e Guattari (1976). Já, o termo "práticas de subjetivação" sugere resistência e exercício de liberdade em relação a esses modos maquínicos de subjetivação e uma estetização, uma produção de si mesmo. No entanto, a análise genealógica interessa-se tanto por modos quanto por formas de subjetivação.

Em síntese, esta perspectiva crítica de análise histórica volta-se para as correlações observáveis numa cultura entre campos de saber, tipos de normatividade e formas de subjetividade, o que implica uma análise de problematizações e jogos de verdade nos quais o sujeito se constitui como sujeito moral, articulada com uma atenção aos movimentos dos dispositivos: suas ações de normalização, seus modos de sujeição, de subjetivação, de assujeitamento, e ainda um olhar para estetizações operadas pelo sujeito sobre si mesmo, além de práticas de resistência e liberdade. Tomados como resultantes de relações de poder, sujeição e assujeitamento também dizem respeito a diferentes efeitos: a sujeição decorre de práticas de objetivação, como o assujeitamento é correlativo de modos de subjetivação, uma vez que envolve uma relação onde alguém se reconhece como sujeito da enunciação ou ação de poder exercida sobre ele. A sujeição supõe o exercício de poder de um sobre outro; no assujeitamento é o próprio sujeito que se a-sujeita, se anula. 


\section{REFERÊNCIAS}

DELEUZE, G.; GUATTARI, F. O Anti-Édipo. Capitalismo e esquizofrenia. Rio de Janeiro: Imago. (Trabalho original publicado em 1972).

FOUCAULT, M. História da sexualidade III: O cuidado de si. Rio de Janeiro: Graal, 1985.

FOUCAULT, M. Vigiar e punir. Petrópolis: Vozes, 1987.

FOUCAULT, M. História da sexualidade I: A vontade de saber. Rio de Janeiro: Graal, 1988a.

FOUCAULT, M. História da sexualidade II: O uso dos prazeres. Rio de Janeiro: Graal, 1988b.

FOUCAULT, M. Nietzsche, Freud, Marx: Theatrum Philosoficum. São Paulo: Princípio, 1997.

FOUCAULT, M. La hermenéutica del sujeto. México: Fondo de Cultura Económica, 2002.

FOUCAULT, M. Eu, Pierre Rivière, que degolei minha mãe, minha irmã e meu irmão. Rio de Janeiro: Graal, 2003.

FOUCAULT, M. Les aveux de la chair. Paris: Gallimard, 2018.

NIETZSCHE, F. A genealogia da moral. São Paulo: Brasiliense, 1988.

PRADO FILHO, K. Considerações acerca do cuidado de si mesmo contemporâneo. In: Tedesco, S; Nascimento, M.L. Ética e subjetividade. Porto Alegre: Sulina, 2009, p. 231-245.

PRADO FILHO, K. (2017). A genealogia como método de análise de práticas e relações de poder. In: Revista de Ciências Humanas; vol.51, s.2, 2017, p. 311-327.

NIETZSCHE, F.(1988). A genealogia da moral. São Paulo: Brasiliense.

PRADO FILHO, K; MARTINS, S. (2007) A subjetividade como objeto da(s) psicologia(s). In: Revista Psicologia \& Sociedade; vol.19, nº3, 2007, p. 14-19.

PRADO FILHO, K.; TETI, M. A cartografia como método para as ciências humanas e sociais. In: Barbaroi/Unisc; vol.1, s.38, 2013, p. 45-59.

$\begin{array}{ll}\text { Histórico } & \text { Submissão: 10/07/2019 } \\ & \text { Revisão: } 25 / 08 / 2019 \\ & \text { Aceite: } 20 / 09 / 2019\end{array}$

Aceite: $20 / 09 / 2019$ 